\title{
Tendencias actuales en técnicas de animación
}

\author{
Jesús PerTíñez LóPEZ \\ Universidad de Granada
}

\section{Resumen:}

La animación actual se encuentra atrapada por una industria cinematográfica que ha apostado toda su creatividad a las técnicas 3D. Superados la fascinación de los primeros adelantos técnicos el futuro de la animación sólo pasa por la revitalización de las técnicas primitivas con software actual.

Palabras clave: animación; técnicas primitivas; nuevas tendencias

\section{New trends in techniques of animation}

\begin{abstract}
:
The current animation is trapped by a film industry that has bet all their creativity to $3 \mathrm{D}$ techniques. Overcome the fascination of the first technical advances the future of animation only happens for the revitalization of primitive techniques with current software.
\end{abstract}

Key Words: animation; primitive techniques; new trends

\section{Referencia normalizada:}

Pertíñez López, J. (2014): Tendencias actuales en técnicas de animación. Historia y Comunicación Social. Vol. 19. Núm. Especial Febrero. Págs. 173-182.

Sumario: 1. El comienzo de la animación experimental. 2. Los pioneros. 2.1 Walter Ruttmann. 2.2 Oskar Fischinger. 2.3 Norman McLaren. 3. Evolución de la animación experimental. 4. La pervivencia de la animación experimental. 4.1. Juguetes ópticos. 4.2. StopMotion. 4.3. Animación "bajo cámara". 4.4. Animación sobre película. 4.5. Animación de líquidos. 5. Referencias bibliográficas.

Desde el inicio de la conciencia artística del hombre, éste ha querido crear el movimiento, dar vida a lo inanimado. Primero se valió del dibujo y la pintura, con personajes ingrávidos, estelas que simulaban su travesía por el espacio. Luego, con el Renacimiento, empezaron a surgir juguetes ópticos que con simples mecanismos mezclaban dos imágenes, un antes y un después en el tiempo. Y esas dos imágenes, se convirtieron en 8 , en 12 , en $20 \ldots$ hasta que en el siglo XIX apareció un nuevo arte destinado a suplantar a las tradicionales, un arte que permitirá crear vida delante del espectador. 


\section{El comienzo de la animación experimental}

Emile Cohl proyecta en 1908 "Fantasmagorias", un corto de animación directa sobre cámara, con una tiza y una pizarra. El procedimiento era sencillo, se va dibujando paso a paso, al mismo tiempo que se fotografía cada ligera modificación del dibujo original. Proyectado a la velocidad adecuada, el dibujo nace ante nosotros, cobra vida y desaparece.

Con esta película inicia una nueva era en el arte del movimiento y la animación tendrá un siglo por delante para desarrollarse hasta sus últimas consecuencias. Al igual que sucedió con el cine, muchos pensaron que estaban ante una nueva diversión de feria, una nueva forma de negocio. Pero otros vieron con claridad que estaban ante el "arte total", una forma de creación que unía dibujo, pintura, escultura, música y cine, lo esperado durante siglos.

Los primeros encontraron su líder en Disney y éste supo responder a las expectativas de animación como negocio de la diversión. Creó un sistema de trabajo en cadena, con obreros especializados en tareas muy concretas, que producían cortos de animación siguiendo las demandas del público. Este sistema funcionó y funciona muy bien, pero el artista queda aplastado por el estilo del estudio, que es el que prevalece, en aras de los estudios del mercado sobre gustos del público.

Pero al mismo tiempo que Disney crea su Mickey, el mundo y especialmente Europa vive un momento cumbre de creación artística, el momento de las "Vanguardias" que revoluciona el arte concebido hasta ahora. Se busca la provocación, el ímpetu, la ruptura, porque después de una guerra tan cruel, ya nada puede ser igual. Estos dos mundos artísticos, el comercial y edulcorado, trabajo en serie, por un lado, y el rupturista, innovador y avanzado, coexistirán durante décadas, si bien el primero, por simple criterio industrial, terminará ocultando al segundo. Animación tradicional y animación experimental llegarán caminos paralelos hasta nuestros días.

\section{Los pioneros}

\subsection{Walter Ruttmann.}

En 1921 se estrena en un teatro de Alemania un corto titulado Lichtspiel, Opus $\mathrm{n}^{\circ} 1^{1}$. Es animación pero no aparecen ratones ni gatos, es pintura en movimiento. El espectador asiste por primera vez a una animación abstracta, donde formas, colores, trazos se mueven por la pantalla al ritmo de la música. Su autor, Walter Ruttmann (Alemania 1887-1941) es un arquitecto que deja su trabajo para dedicarse a la pintura y a la música porque ve con claridad el potencial que tiene la animación como forma creativa. Sería la primera de una serie de tres películas que denominaría Absolute films. La técnica era la misma que utilizó 13 años atrás Emile Cohl, pintura sobre cristal, y capturando con la cámara cada modificación. Pero Ruttmann también añadío 
figuras geométricas de papel, y varias capas de cristal lo que aumentaba la sensación de profundidad. La película se rodó en blanco y negro y una vez revelada la coloreaba con los tres métodos comunes en ese momento: tiñendo, entonando y coloreando a mano (tinting, toning, and hand-tinting).

Ruttmann comprende que la animación no puede quedar al margen de las nuevas tendencias artísticas y por eso prefiere las composiciones abstractas, que tienen como referente a Kandinsky. La abstracción le permite jugar con las formas geométricas simples y sus movimientos coordinados, círculos pendulares, triángulos ásperos y fluidos simuosos. Pero también le sirve para sincronizarlos con la música (partitura de Max Butting) como hasta ahora no se había visto. Este pionero alemán ofrecía un espectáculo en una sala nunca visto hasta entonces, formas geométricas que bailan al ritmo de una música contemporánea y culta.

\subsection{Oskar Fischinger}

Si Ruttmann es el iniciador de la animación experimental, el auténtico genio fue Oskar Fischinger (Alemania, 1900-1967). Al igual que el primero, Fischinger era un ingeniero que quedó sorprendido por las posibilidades creativas de la animación experimental al presenciar en directo los trabajos de Ruttmann. Precisamente su formación tecnológica le ayudará a inventar nuevas técnicas, nuevas herramientas que engrandecerán la animación, siempre buscando la creación de espectáculos músico-visuales.

Trabajó con Fritz Lang, en los Estudios UFA, para dedicarse mas tarde exclusivamente a producir estudios en blanco y negro sincronizados con música, de enorme éxito en América, Europa y Japón. La II Guerra Mundial le empujó a Hollywood donde trabajó para la Paramount (1936), MGM (1937) y Disney (1938-9), si bien de forma efímera pues no pudo integrarse en un trabajo en cadena.

Entre sus invenciones queremos destacar las siguientes:

- Construcciones geométricas de cera, que al aplicarles un foco de calor se van derritiendo paso a paso, fotograma a fotograma. Coloreaba la cera con pigmentos para crear formas mas impactantes.

- Como perfeccionamiento del anterior, ideó una especie de guillotina que iba cortando finas láminas de un bloque de cera con múltiples colores. A cada corte le hacía una foto, por lo que al reproducirse, el espectador observa unas formas caprichosas de colores que se mueven por la pantalla. Además, le añadió un cristal delante en el que trabajada con la misma técnica que Ruttmann.

- Fue uno de los primeros en realizar animación de fluidos.

- En 1926 creó uno de los aparatos más ingeniosos realizados para animación porque por primera vez alguien se proponía hacer animación en directo, ante el público. El compositor húngaro Alexander Laszlo le propuso ese reto mientras él ejecutaba sus recitales de piano. Crearon un espectáculo que llamaron 
Farblicht-musik (Color-Luz-Música). El invento consistía en una membrana vertical, elástica, de tamaño suficiente para ocultar a una persona detrás y con una columna a ambos lados. Esa columna, además de servir de soporte, llevaba ocultos focos de colores que proyectaban una luz rasante en la membrana. Los focos tenían sus interruptores a los pies del artista con lo que podía fácilmente encenderlos y apagarlos a voluntar. El espectáculo se creaba cuando Fischinger, detrás de la membrana, la empujaba con los dedos. La membrana sobresalía y recibía la luz rasante. En un escenario oscuro, el público sólo veía colores en formas indefinidas que se movían al ritmo de la música.

- Pero lo que más nos interesa son sus avances para convertir de una forma gráfica la música en imágenes. Los primeros intentos los llamó Graph of dynamics. Se trataba de un ejercicio gestual, rápido, por el que iba dibujando en tiras de papel lo que le sugería la música que estaba escuchando, líneas abstractas en su mayoría. Estos trabajos los fue depurando hasta inventar una técnica de geometrización de imágenes en largas tiras de papel que luego filmaba sobre película. El resultado era sorprendente y atrajo rápidamente la atención de los principales artistas de la época.

- Además buscaba experimentar con el sonido sintético dibujado y así completó su primera película en color Kreise/Circles ${ }^{2}$, 1933, empleando el proceso GasparColor, un sistema de sustracción a tres colores, empleando tres capas de emulsión sensibles en distintos espectros. Se trata de una composición muy dinámica y ligera, de movimientos a veces hipnóticos, que simula la proyección de focos de colores muy vivos sobre un fondo oscuro, unos se alejan o acercan dando una fuerte sensación de profundidad. Sus posteriores películas en color, Muratti Marches On y Composition in Blue recibieron tan buenas críticas y clamor popular, que Paramount le ofreció un contrato.

- Esta creciente investigación para convertir en imágenes la música, culmina en Poema Óptico ${ }^{3}$, 1937. Para ello construyó la estructura de un cubo en cuyo interior colocó multitud de hilos transparentes. De ellos iba colgando figuras geométricas de cartulina que movía fotograma a fotograma al ritmo de la música, creando una danza tridimensional y sorprendente porque estamos observando distintos tipos de iluminación, sombras arrojadas...

- Fischinger tuvo todo el reconocimiento que puede esperar un artista. Con Motion Painting No.1, 1947, recibió el Gran Premio en el Festival de Cine Experimental de Bruselas de 1949. En ella emplea óleo sobre distintas capas de cristal de $18 \times 24$ ", grabando cada pincelada en un fotograma de la película, de modo que solo costara el precio de la pintura y del rollo de película. Un impresionante trabajo, rico y abigarrado, que va superponiendo pinceladas sobre pinceladas y, en ocasiones, composiciones sobre otras que quedan en la capa de cristal inferior ${ }^{4}$. 


\subsection{Norman McLaren}

Fischinger descubrió la animación experimental gracias a Ruttmann, y Normam McLaren (Escocia 1914-1987) gracias a Fischinger. A este escocés le debemos la invención de una de las técnicas mas utilizadas en esta faceta de la animación: la pintura sobre celuloide. Utilizó la película sin impresionar como soporte, añadiendo acuarela, tintas, y luego rayando, incluyendo objetos...

El trabajo de McLaren está unido al de la National Film Board de Canadá, centro para el que comenzó a trabajar durante la Segunda Guerra Mundial precisamente por sus descubrimientos en animación experimental. Con la técnica de McLaren se podían hacer películas con muy bajo coste y muy rápidas. Con Love on the Wing 1938, McLaren hizo una demostración de sus propias técnicas de animación. Empleando fondos inspirados en los paisajes de Dalí desarrolla una ágil y cómica transformación de líneas blancas, un grafismo especialmente suelto que recuerda a las primeras animaciones como Fantasmagorie.

Sus películas han ganado más de 200 galardones. Neighbours ${ }^{5}$, realizada en 1952 , ganó un Oscar en ese mismo año, y Blinkity Blank recibió la Palma de Oro de Cortos en el Festival de Cannes de 1955. En la primera, una narrativa personal originada por las vivencias de la guerra, emplea la pixilación para captar el movimiento de los personajes y los objetos mediante la toma de varios fotogramas en cada tiempo, y lo hace de manera que da a la acción un aspecto frenético, muy ajustado a la línea narrativa de la pieza. En Blinkity Blank, vuelve a la técnica de la manipulación directa de la película: rasca y pinta formas sencillas y palpitantes que nos descubren la impronta inmediata de la mano de McLaren, que asocia forma y sonido, color y movimiento . $^{6}$

Consideramos, sin duda, que estos dos genios, Fischinger y McLaren, son los padres de la animación experimental actual, los creadores de todas las técnicas alternativas a la tradicional, al acetato, a los fotogramas claves y al betweening. Los estudios sobre este tema pueden incluir a otros artistas como pioneros, pero ninguno como ellos convirtieron la animación en una obra de arte.

\section{Evolución de la animación experimental}

Como hemos podido comprobar, la animación experimental tuvo una época gloriosa con artistas de reconocida valía artística. Pero la industria de la animación fue implacable con ellos y pasaron a un segundo nivel, para público minoritario y escogido. Así se crearon dos caminos paralelos, uno comercial que buscaba el aplauso del gran público en el cine y posteriormente en la televisión; y otro experimental, en salas de exposiciones, museos y salas de música. Hubo grandes artistas que continuaron la obra de los tres genios que hemos visto: 
- Harry Smith, que combinaba las expresiones místicas y artísticas directamente sobre celuloide y proyectadas en espectáculos de jazz en directo con Dizzy Gillespie y Thelonius Monk

- Dwinell Grant, con composiciones de figuras geométricas con iluminación real, destellos de colores y proyección estereoscópica, décadas antes que el 3D)

- Hy Hirsh, mezclando personajes reales, figuras geométricas, luz...

- John Whitney, - Jordan Belson, etc, etc.

Son artistas desconocidos para el gran público pero con una trayectoria creativa que ha transcendido. Los animadores experimentales fueron los primeros en utilizar tecnología electrónica en sus creaciones, en crear en la década de los 60 del siglo pasado las primeras animaciones por ordenador (Stan Vanderbeek, Lillian Schwartz, Larry Cuba, y Ed Emshwiller, el primer creador de un 3D por ordenador en 1979).

La animación tradicional no ha sido ciega a estos avances, tanto técnicos como artísticos y siempre ha estado dispuesta a incluirlos en sus producciones para actualizar sus productos.

Esta relación entre hermano mayor y hermano menor se rompe a mediados de los años 80 , cuando el ordenador se convierte en una herramienta imprescindible en la creación artística. Las productoras de animación empiezan un camino de no retorno, sustituyendo a los dibujantes de las distintas fases de esa producción en cadena por el proceso mecánico. Primero fueron los coloreadores (ya no hacen falta pinceles ni acrílicos, basta un click), luego los intercaladores (el ordenador crea el movimiento intermedio entre fotogramas claves) y con los primeros software de 3D la creación de personajes se limitó a la construcción digital del personaje, con su armazón correspondiente. En 1995 aparece Toy Story, la primera película de animación enteramente digital, creadora de una estética que sigue triunfando en las salas comerciales y con ella empezó la búsqueda de lo más real posible, personajes que parezcan reales, que se muevan como reales. Y hace algunos años que ya llegamos a eso y ya ni siquiera hace falta dibujar porque con capturadoras de movimiento el personaje real se convierte en animado con un solo click.

No sabemos cúal es el siguiente paso, quizás porque no existe. Si buscábamos el parecido con la realidad, engañar al espectador, ya está conseguido. Pero no hay un más allá, esa vía está agotada. Aún así, los grandes estudios se siguen copiando a sí mismos una y otra vez, explotando una técnica que a fuerza de repetirla ha producido hartazgo. Vemos los mismos personajes, intercambiables de una historia a otra, de un estudio a otro, todos realizados bajo el mismo patrón, la misma estética, la misma luz, la misma textura. Y fundamentados en un aspecto puramente comercial: es más barato y más fácil.

Al menos eso dicen, pero no es cierto porque los medios técnicos nos permiten desde hace años producir animaciones con cualquier tipo de técnica con bajos costes, 
sin perder creatividad. Quizás esa sea la cuestión, en un proceso de producción en cadena no se necesitan creativos sino mano de obra barata, no hacen falta personas que sepan de texturas, color, luces, sino que manejen un software concreto.

Por todo ello, pensamos que la única vía de futuro de la animación es la vuelta a los orígenes, es retomar las técnicas de animación experimental y actualizarlas con nuevas herramientas.

\section{La pervivencia de la animación experimental}

Para demostrar nuestra afirmación de que la animación experimental está mas viva que nunca, expondremos una pequeña muestra de técnicas primitivas comparando las creaciones de los pioneros con artistas actuales.

\subsection{Juguetes ópticos}

A finales del siglo XIX aparecen unos artefactos que creaban la ilusión de movimiento mediante pocas imágenes estáticas. Un simple taumatropo, con dos imágenes dio paso al flipbook, un conjunto de imágenes que se pasaban rápidamente con la mano. En la actualidad Juan Fontanieve, joven estadounidense recrea esos flipbook con piezas de relojes y dibujos de acuarela ${ }^{7}$. Eric Dyer utiliza el mecanismo de un zootropo para sorprendernos con videos impactantes ${ }^{8}$

\subsection{StopMotion}

Es sin duda una de las técnicas más creativas, puesto que permite dar vida a cualquier objeto cotidiano. Tiene muchas variantes y desde el inicio de la animación fue una de las técnicas preferida por los artistas experimentales. Man Ray en 1923 creó una animación con puntillas, chinchetas, muelles. Marcel Duchamp o Moholy-Nagy también usaron esta técnica para sus cortos. En la actualidad es una de las técnicas preferidas sobre todo con personajes de plastilina o látex, con una estética mucho mas agradable y exitosa que el 3D, ya que los creadores disponen de más libertad. Pero en esta defensa de la animación experimental, queremos mencionar algunos ejemplos: Shugo Tokumaru ha creado en 2013 un video, Katachi, donde mezcla el stopmotion tradicional con siluetas tridimensionales, en una vuelta de tuerca más hacia la excelencia artística9 ${ }^{9}$. Mike Please utiliza un material parecido a la espuma de alta densidad para confeccionar un mundo aséptico y enigmático ${ }^{10}$

\subsection{Animación "bajo cámara"}

Si hay un artista que ha sabido convertir en obras maestras sus animaciones ha sido William Kentridge. Utilizando las herramientas tradicionales de las artes plásticas, fundamentalmente carboncillo, va creando ante la cámara auténticos cuadros móviles 
que se construyen-destruyen ante nuestros ojos. En su obra "Breathe" va mas lejos, jugando con el aire y el papel ${ }^{11}$.

Esta técnica, en la que no interviene el ordenador, tiene unas posibilidades infinitas. Joan Gratz las ha aprovechado uniendo la animación 2D con la tridimensional, utilizando la plastilina como pintura. Sus obras siguen causando asombro ${ }^{12}$.

\subsection{Animación sobre película}

Como hemos mencionado, Fischinger primero y especialmente McLaren utilizaron está técnica de animación directa. Hay autores contemporáneos que la siguen usando con el mismo procedimiento, película de celuloide virgen, pintura directa y montaje sobre proyector. Pero se usa cada vez menos porque cada vez es mas difícil y caro encontrar celuloide y como consecuencia, encontrar proyectores de $35 \mathrm{~mm}$. En el Departamento de Dibujo de la UGR, el Grupo de Investigación HUM73 viene trabajando en recuperar las técnicas primitivas de animación experimental adaptadas a medios digitales y especialmente, la técnica de pintura sobre celuloide.

Hemos conseguido encontrar un método alternativo al celuloide con unos resultados sorprendentes. Este nuevo método se basa en la utilización de una opción del programa informático Adobe que pasa prácticamente desapercibida, tanto es así, que en las últimas versiones del paquete, la empresa ha decidido suprimirlo. Esta opción Filmstrip nos permite la creación de un celuloide virtual que sustituye al tradicional. En esta película informática podemos pintar, pegar, clonar, cualquier cosa que se nos ocurra $^{13}$.

\subsection{Animación de líquidos}

Al igual que la técnica anterior, Fischinger comenzó a experimental con la diferencia de densidad de líquidos para crear animaciones directas. Lo más nuevo que hemos visto es la obra de Kim Pimmel, con agua jabonosa y tinta ${ }^{14}$.

Los ejemplos que podemos ofrecer son infinitos porque los creativos que están trabajando en este campo aumentan cada día. Nuestra obligación es convencer al gran público que estas técnicas se pueden usar en películas comerciales y que tendrían el mismo éxito o más que las de 3D. Algunas productoras parecen que empiezan a darse cuenta. Disney nos ofrece una maravilla como Paperman, una animación en blanco y negro, sin canciones ni diálogos, donde apreciamos el trazo del lápiz y casi la mancha de la cera. Todas las animaciones candidatas a los Oscar de 2013 al mejor corto, todas rehúyen de la animación 3D. En Adam y Dog, aparecen las líneas quebradas y las manchas de acuarela. Fresh Guacamole y Heads over Heels recurren al stopmotion. Y Maggie Simpson the longest daycare, vuelve a la animación tradicional, dibujo a dibujo.

La animación está evolucionando porque la tecnología permite materializar cualquier sueño. Podemos resumir que el futuro de la animación se encuentra en:

1. La vuelta a las técnicas primitivas pero apoyadas en las nuevas tecnologías. 
2. Su utilización como soporte para mensajes sociales, políticos o didácticos

3. Intermedia: animación de sonidos, de luz

4. Soportes alternativos. Ya no basta con la pantalla de cine o de tv. Hay que hacer animaciones para soportes móviles y para nuevos espacios urbanos.

\section{Bibliografía}

\subsection{Libros:}

MORITZ, W. (2004). Optical Poetry. The life and work of Oskar Fischinger. John Libbey Publishing. UK.

POSNER, B. (2001). Unseen Cinema. Early American Avant-garde film 1893-1941. Black Thistle Press. New York

RUSSETT, R.; STARR, C. (1988). Experimental Animation. Origins of a new art. A Da Capo Paperback. New York

SOLOMON, C. (1994). Enchanted Drawings. History of Animation. Wings Books. New York. Avenel, New Jersey

WELLS, P.; HARDSTAFF, J. (2008). Re-imagining animation. The changing face of the moving image. AVA Publishing. Suiza.

5.2 Artículos en publicaciones web:

http://vimeo.com/channels/thezone. Canal de video dedicado a la animación experimental

\section{Notas}

1 http://www.youtube.com/watch?v=YApHMHjzdn4. [8 de febrero de 2013].

2 http://vimeo.com/55181698. [20 de septiembre de 2013].

3 http://vimeo.com/43103220. [20 de septiembre de 2013].

4 MORITZ, W. Optical Poetry. The life and work of Oskar Fischinger. UK. John Libbey Publishing. 2004

5 http://www.youtube.com/watch?v=4YAYGi8rQag. [20 de septiembre de 2013].

6 http://www.youtube.com/watch?v=GkAhpQZrMZo. [20 de septiembre de 2013].

7 http://vimeo.com/65852568. [20 de septiembre de 2013].

8 http://www.ericdyer.com/. [20 de septiembre de 2013].

9 http://vimeo.com/58022280. [20 de septiembre de 2013].

$10 \mathrm{http} / / /$ vimeo.com/channels/thezone/49749980. [20 de septiembre de 2013]. 
11 http://www.youtube.com/watch?v=ja4Wk7g6sdE. [20 de septiembre de 2013].

12 http://www.gratzfilm.com/Gratzfilm/Joan_C__Gratz.html. [22 de septiembre de 2013].

$13 \mathrm{https} / / /$ www.youtube.com/watch?v=mJYE0F6i2ns. [22 de septiembre de 2013].

$14 \mathrm{http} / / /$ vimeo.com/28304264. [22 de septiembre de 2013].

\section{El autor}

Jesús Pertiñez López es profesor titular del departamento de dibujo en la Facultad de Bellas Artes de la Universidad de Granada. Licenciado en Bellas Artes por la Universidad de Sevilla (1988) y Doctor en Bellas Artes por la Universidad de Granada (1993). Ha participado en numerosos proyectos de $\mathrm{I}+\mathrm{D}+\mathrm{i}$ sobre sus áreas de investigación así como también ha publicado numerosos artículos sobre ilustración, dibujos animados y Televisión. 